\title{
Outcomes of Birmingham Hip Resurfacing: A Systematic Review
}

Steve Karas, DSc, PT, CMPT, OCS

\author{
Author's Affiliation: \\ Chatham University, Pittsburgh, PA, \\ USA \\ * Corresponding Author; \\ Address: Physical Therapy \\ Department, Chatham University, \\ USA \\ E-mail: skaras@chatham.edu
}

Received: Aug 01, 2011

Accepted: Oct 03, 2011

Key Words: Hip Resurfacing; Birmingham Hip Resurfacing; Hip Resurfacing function; Hip resurfacing outcomes

\begin{abstract}
Purpose: We performed a systematic review to assess the functional outcomes of Birmingham Hip Resurfacing as reported in peer-reviewed literature.

Methods: We performed a computerized search on the data sources up to February 2011. The following text and key words were searched: "Birmingham hip", "Birmingham hip resurfacing” and "Hip resurfacing”. Each of these key words was again searched with "outcomes" following them. We also hand searched the bibliographies of the retrieved articles and our own files to identify specifically relevant articles.

Results: Fourteen retrospective studies and three prospective studies were included for review. Each of these studies was evaluated by the criteria given by Sackett and AACPDM. The design, patient criteria, intervention, outcomes, duration of follow up and results of the research were reported.

Conclusions: Although the technique of BHR does allow the femur to be spared, claims that it may allow patients to be more active need to be further investigated.
\end{abstract}

Asian Journal of Sports Medicine, Volume 3 (Number 1), Mar 2012, Pages: 1-7

\section{INTRODUCTION}

Hip pathology is a common diagnosis that can cause pain and limit activity. In a younger population hip pain commonly occurs from pathology to the labrum ${ }^{[1]}$. Progressive degeneration in these patients may eventually lead to osteoarthritis $(\mathrm{OA})^{[2,3]}$. It is estimated that $0.4 \%$ to $27 \%$ of adults have some form of hip osteoarthritis ${ }^{[4]}$. The traditional surgical treatment for those with OA who have failed conservative treatment is total hip arthroplasty (THA). However, THA has been reported to fail in younger patients with more active lifestyles ${ }^{[5-7]}$. Recently, hip resurfacing (HR) has emerged as a relatively new surgery that has potential advantage to eliminate these failure issues encountered with THA in select individuals. There are a variety of devices that are options for HR and they include; Durom Hybrid System by Zimmer, Conserve Plus by Wright, Cormet MoM by Corin, and the Birmingham
HR (BHR, Smith \& Nephew Inc., Memphis, TN, USA) system by Smith and Nephew.

Specifically, Birmingham Hip Resurfacing is said to "allow you to return to most activities, including impact activities," according to the Smith and Nephew website. This direct to patient advertising has had an effect on patient education. In a study considering a group of patients presenting to one clinic for consultation for hip pain, $41 \%$ were aware of $\mathrm{HR}^{[8]}$. Of these patients $46 \%$ learned of the procedure from the internet, $42 \%$ through family or friends, and only $19 \%$ from an orthopedic surgeon. A majority of these patients preferred to have HR and $82 \%$ felt that it was safer than THA.

Despite its technical challenge BHR has grown in popularity around the world ${ }^{[9]}$. This new procedure was approved by the FDA in 2006, and is now in use in the United States ${ }^{[10]}$. The primary aim of BHR may not be return to a higher level of function; it simply may be 
to decrease pain from hip osteoarthritis for a period of time before a revision is needed. BHR may decrease this pain to the equivalent level of a THA, while still preserving the femur. However, more active patients considering this surgical option will need to be educated on its long-term outcomes and their potential to return to sporting activities. The purpose of this paper is to provide a systematic review of the current literature available for the functional outcomes of BHR.

\section{METHODS AND SUBJECTS}

We performed a computerized search of publications listed in the electronic data bases CINAHL Plus with Full Text, Medline (Ovid), and SPORT Discuss up to February 2011. The following text and key words were searched: "Birmingham hip", "Birmingham hip resurfacing" and "Hip resurfacing". Each of these key words was again searched with "outcomes" following them. We also searched the bibliographies of the retrieved articles and our own files to identify specifically relevant articles.

\section{Study Selection:}

Studies were included for review if: 1) patients received Birmingham Hip resurfacing, 2) an outcome measure of any type was completed and 3) a portion of the group whose outcome was assessed had received Birmingham Hip resurfacing.

\section{Data Extraction and quality assessment:}

The investigator independently extracted data using a standardized form. Data were extracted for study design, patient inclusion, patient exclusion, outcomes assessed, duration of follow up and results. Not every study had all of this data. No attempt was made to ascertain quality of the research since the intent of the paper was to report on specific outcomes of a specific surgery. The brevity of the literature required us to consider most of the research we identified.

\section{Study Identification and selection:}

Using the predefined search strategy, 315 titles were returned. Many of these titles were repeated in each search. Of these, 18 titles were identified as eligible for the review.

\section{Study characteristics:}

Detailed characteristics of the author and year of publication, Sackett level of evidence ${ }^{[11]}$, and quality score based on AACPDM (www.aacpdm.org), study design, patient inclusion, patient exclusion, intervention, outcomes assessed, and duration of follow up and results are available in Table 1.

Three prospective studies were identified. Two had outcomes pre and post-operatively and one issued a post-operative employment survey. Fifteen retrospective studies were identified. Six with post operative outcomes, three with post operative surveys, five with pre and post-op outcomes, and one with a pre and post-op questionnaire. No randomized control trials were identified. No studies with control groups were identified. The maximum follow up for any research was 10 years using a survey or outcome tools.

\section{Operative method:}

Eleven of the papers identified did not provide descriptions of the operative method, other than to identify it as a BHR. Four identified the BHR approach as posterior ${ }^{[12-16]}$ one as extended posterior ${ }^{[17]}$ and one as modified extended posterior ${ }^{[18]}$. No research was identified that examined a specific operative method of BHR and its effects on postoperative outcomes.

\section{Rehabilitation:}

Four of the articles discussed post-operative rehabilitation. One study stated that the post-operative protocols varied ${ }^{[12]}$. Another study stated that the early rehabilitation was "slow", but eventually was "normal" [15]. Two studies included specific post-operative criteria. One encouraged immediate full weight bearing, but allowed the use of one or two canes. ${ }^{[13]}$ Another implemented traditional THA precautions for six weeks, dictated partial weight bearing for the first week, followed by the use of a cane(s) for one to two weeks as needed ${ }^{[19]}$. No research was identified that 


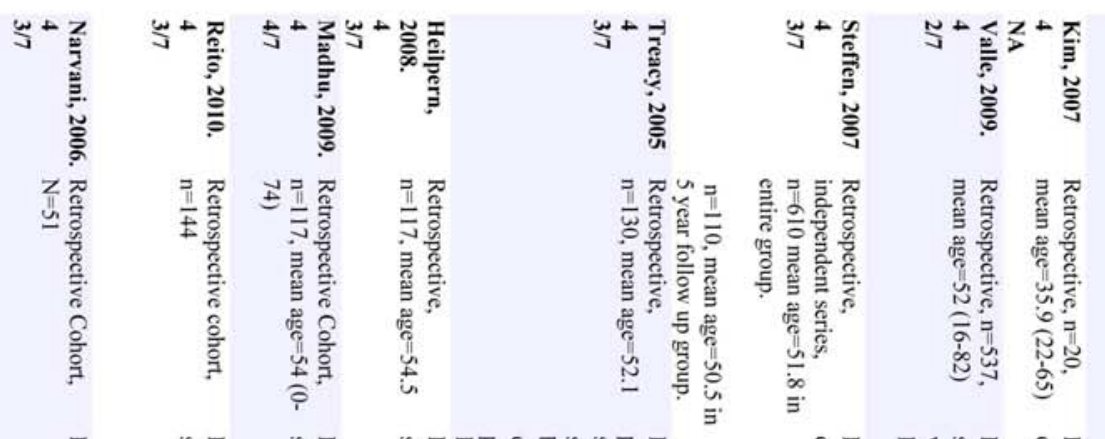

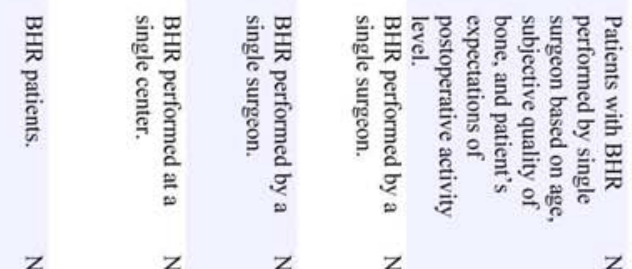

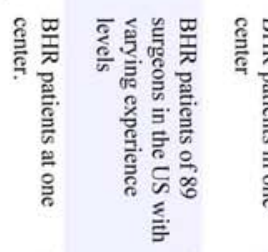

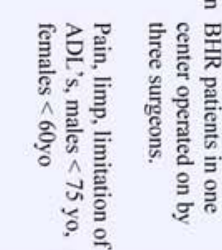

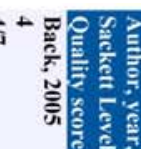

$\xi \quad z \quad z \quad z$

z

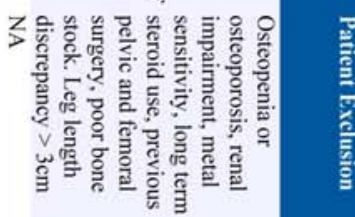

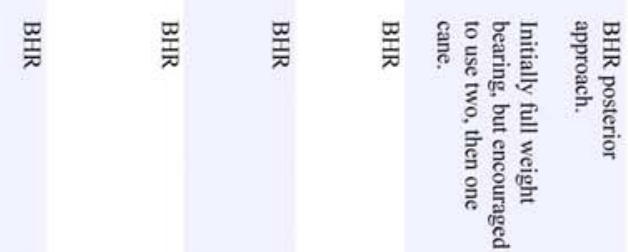
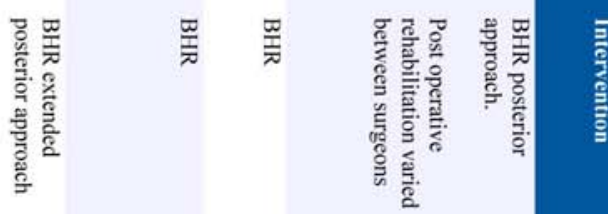

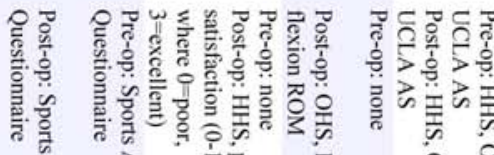

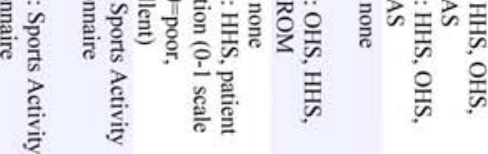

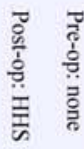

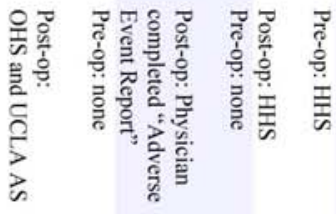

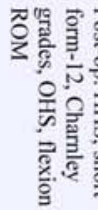

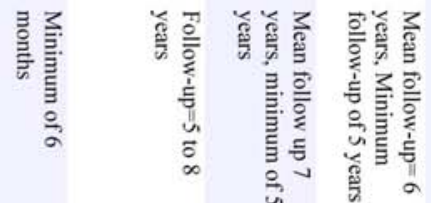

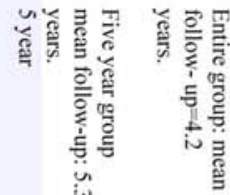

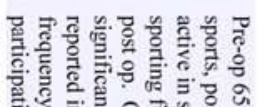

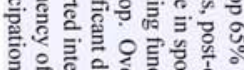

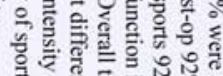

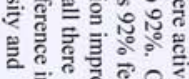

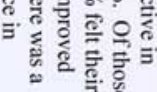

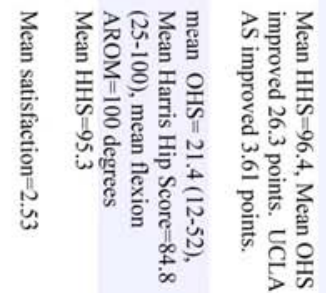

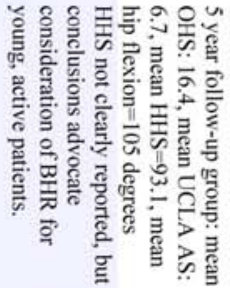

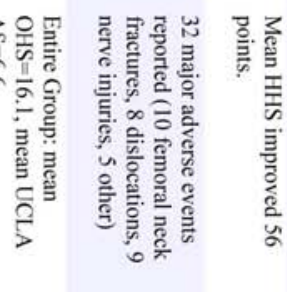

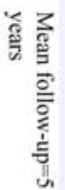

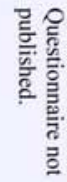

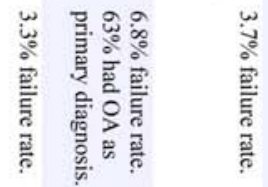
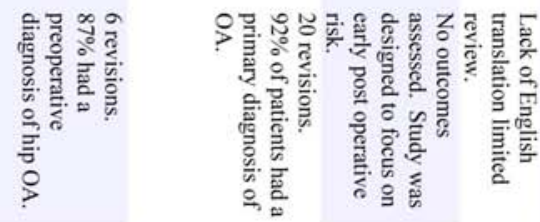

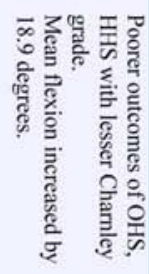

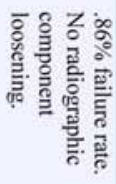



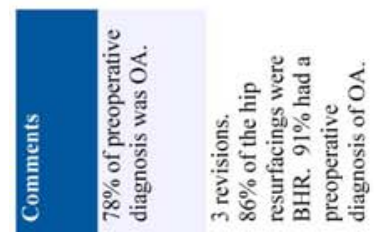

$\stackrel{3}{3} \geqq$

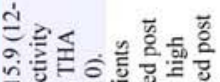

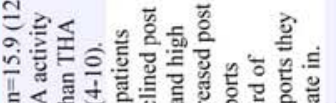

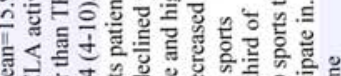

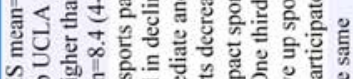

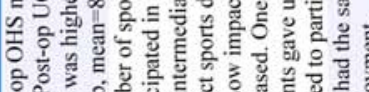

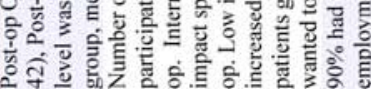

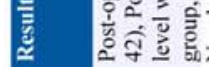

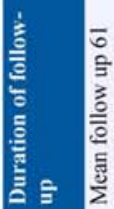

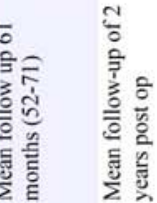

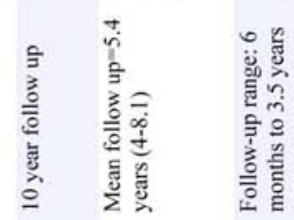

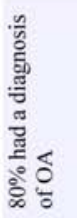

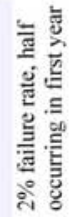

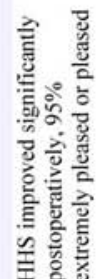

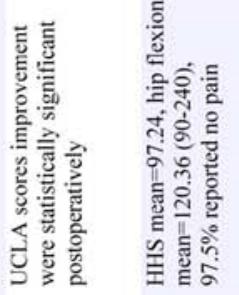

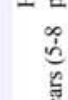

政



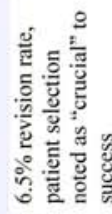

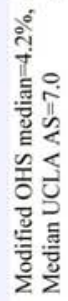

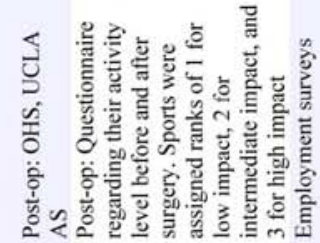

政客

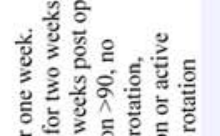

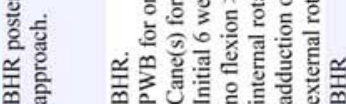

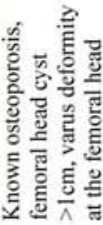

8 .

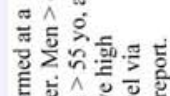

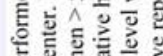

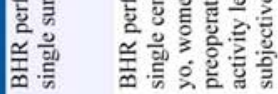

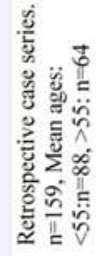

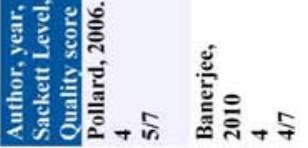

范

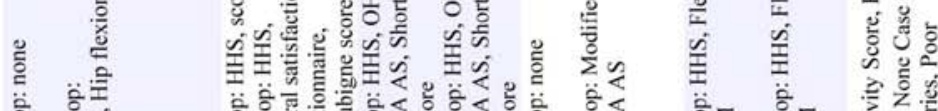

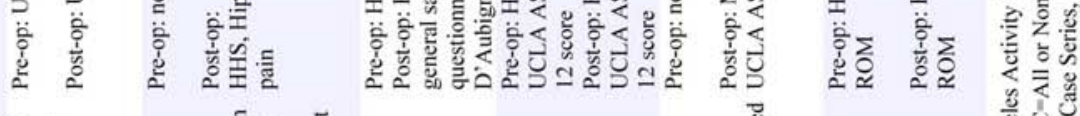

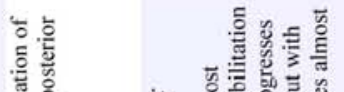

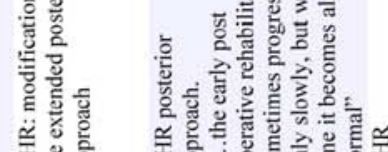

号

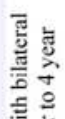

政产

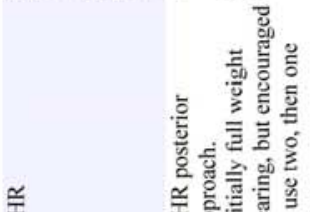

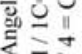

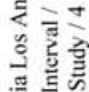

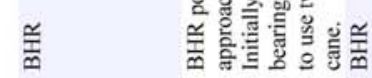

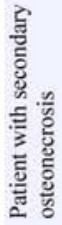

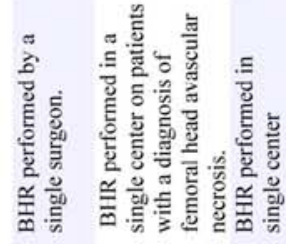

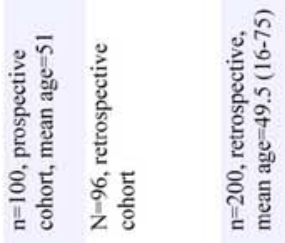

s

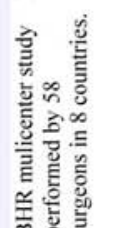

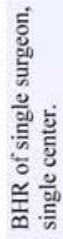

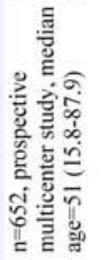

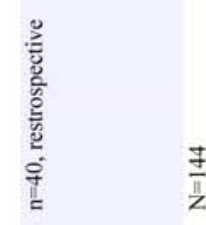

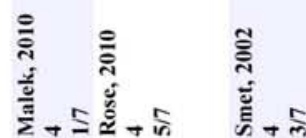

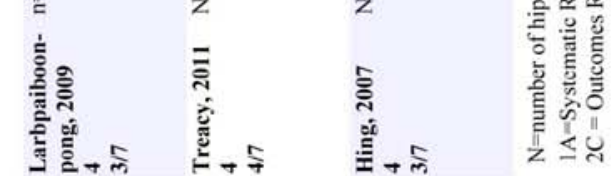


evaluated a specific postoperative rehabilitative course.

\section{Duration of follow-up:}

The duration of follow-up varied significantly among the research from six months to ten years. Seven studies had group results for less than five years $\left[12,15,17,19-22\right.$, two for exactly five years ${ }^{[13,23]}$ and eight for longer than five years ${ }^{[14,16,17,24-28]}$.

\section{RESULTS}

Of the seven studies that included pre and postoperative outcomes three documented increases in hip flexion active range of motion (AROM), one by a mean of 18.9 degrees, one noted a significant improvement, and another showed a mean hip flexion of 120.36 degrees ${ }^{[12,29,15]}$. Six assessed the Harris Hip Score (HHS) and noted the following: an increase of 56, means of 96.4 and 84.8, poorer outcomes with lesser Charnley grades, one simply noted improvement, and two noted significant improvement ${ }^{[12,21,23-25,28,29]}$. The four studies which noted the Oxford Hip Score (OHS) found means of 16.1 and 16.4, a mean 26.3 improvement, a mean of 21.4, and poorer outcomes with lower Charnley grades ${ }^{[12,24,25]}$. One study reported the median modified OHS as $4.2 \%$ using the Pynsent method ${ }^{[16]}$. The five that documented the University of California Los Angeles Activity Score (UCLA AS) noted means of 6.6 and 6.7, a 3.61 improvement, a mean of 8.4, statistical improvement, and a median of $7.0^{[14,16-18,24]}$.

One study included a pre and post-operative questionnaire and had participants' complete information on sports participation before and after BHR. 65\% were active in sports preoperatively, and this increased to $92 \%$ postoperatively. 92\% reported that their sporting function had improved. There was a significant difference in the intensity and frequency of sports participation ${ }^{[21]}$.

Of the six studies which detailed only post-operative outcomes, those that used the HHS reported means of 95.3, 97.24 and $84.8^{[15,25,26]}$. One author reported that the HHS had him conclude that BHR was effective for a younger, active population. The scores were not reported ${ }^{[13]}$. On those that used the UCLA AS provided means of $8.4^{[14]}$ and $6.7^{[17]}$ Studies reporting the OHS listed means of $15.9^{[14]}$ and $16.4^{[17]}$ One study reported satisfaction means of 2.53 out of a 0 (poor) to 3 (excellent) scale ${ }^{[26]}$. Finally, where AROM hip flexion was considered, the mean was 100 degrees [24].

The three studies which contained only post operative questionnaires included reports of adverse events, sports participation, and employment status $[19,20,27]$. Adverse events were less than one percent. Sports participation was reported to have declined in high and intermediate impact activities and increased in low impact activities. One third of the subjects reported they had to give up sports that they intended on continuing. Employment surveys showed $90 \%$ of patients' employment was not affected.

\section{Limitations:}

The research identified using outcomes to report on BHR falls into the Level of Evidence: 4 of the Sackett scale. Level 4 is defined as a "Case series and poor quality cohort and case-control studies" ${ }^{[11]}$. This limitation in research design does not allow for a complete appreciation of the outcomes of BHR, either on its own or in comparison with THA, arthroscopic procedures, other hip resurfacing systems, or absence of surgical intervention.

The quality assessment scale as defined by AACPDM in the included research had a mean of 3.25 on the 7 point scale. Only three of the studies presented clear inclusion and exclusion criteria. Six of the studies clearly noted the surgical approach utilized, while four contained comments concerning the post-operative care and/or rehabilitation. While some of the outcome tools used, such as the HHS, OHS, and UCLA AS have been shown to be valid, their reliability when applied to BHR has not yet been established. None of the studies utilized any type of blinding when assessing the patients. Use of statistical evaluation and power analysis varied in the research. Finally, the dropout/loss rate was typically below the established $20 \%$ and reported failure rates were acceptable. 


\section{CONCLUSION}

BHR is currently being used worldwide as a means to delay THA in the younger patient with OA of the hip or as an option for the more active individual. BHR is chosen in active individuals because a higher level of activity post THA is typically not advised and can be damaging to the implant. In addition, the patient's own femur is spared due to the surgical method.

While the sparing of the femur does occur, whether a patient can maintain a high level of function post BHR of the literature suggests that more complete research is needed. We would suggest utilization of outcome tools such as the Western Ontario and McMaster Universities' Osteoarthritis Index (WOMAC) and the HHS. These outcome tools have been validated ${ }^{[30]}$. These measures should be assessed pre-operatively and post-operatively as part of the evaluation and follow up process. In addition they could be used for comparisons of various surgical approaches and post-operative rehabilitation protocols. Clearer inclusion and exclusion criteria as well as longer follow-up would also add to the body of research. Once these questions have been addressed, we may better educate our patients who are considering this relatively new procedure.

\section{REFERENCES}

1. Martin RL, Enseki KR, Draovitch P, et al. Acetabular Labral tears of the hip: examination and diagnostic challenges. J Orthop Sports Phys Ther 2006;36:503-15.

2. McCarthy JC, Noble PC, Schuck MR, et al. The Otto E. Aufranc Award: The role of labral lesions to development of early degenerative hip disease. Clin Orthop Relat Res 2001;393:25-37.

3. McCarthy JC, Noble PC, Schuck MR, et al. The watershed labral lesion: its relation to early arthritis of the hip. J Arthroplasty 2001; 16:81-7.

4. Dagenais S, Garbedian S, Wai EK. Systematic review of the prevalence of radiographic primary hip osteoarthritis. Clin Orthop Relat Res 2009;467:623-37.

5. Tennent T, Goddard NJ. Current attitudes to total hip replacement in the younger patient: results of a national survey. Ann R Coll Surg Engl 2000;82:33-8.

6. Lewthwaite S, Squires B, Gie G, et al. The Exeter universal hip replacement for the young patient - 10 to 17 years follow up. $J$ Bone Joint Surg Br 2008;90:537.

7. Howcroft D, Head M, Steele N. Bearing surfaces in the young patient: out with the old and in with the new? Curr Orthop. 2008;22: 177-84.

8. Murphy TP, Trousdale RT, Pagnano MW, Mabry T, Sierra RJ. Patient's Perceptions of Hip Resurfacing Arthroplasty. Orthopedics 2009;23:730.

9. Della Valle CJ, Nunley RM, Raterman SJ, Barrack RL. Initial American Experience with Hip Resurfacing Following FDA Approval. Clin Orthop Relat Res 2008;467:72-78.

10. U.S. Food and Drug Administration, Department of Health and Human Services. Birmingham Hip Resurfacing PO40033 approval letter, May 9, 2006. Available at: http://www.accessdata.fda.gov/scripts/cdrh/cfdocs/cfTopic/pma/pma.cfm?num=P040033. Retrieved: Aug 1, 2011.

11. Sackett DL, Richardson W, Rosenberg W, Haynes R. Evidence-Based Medicine: How to Practice and Teach EBM. $2^{\text {nd }}$ ed. London: Churchill Livingstone. 2003.

12. Back DL, Dalziel R, Young D, Shimmin A. Early Results of primary Birmingham hip resurfacings early results of primary Birmingham hip resurfacings. An independent prospective study of the first 230 hips. J Bone Joint Surg. 2005;87:324-9.

13. Treacy R, McBryde CW, Pynsent P. Birmingham Hip Resurfacing Arthroplasty, A minimum follow-up of five years. J Bone Joint Surg Br 2005;87:167-70.

14. Pollard T, Baker RP, Eastaugh-Waring SJ, Bannister GC. Treatment of the young active patient with osteoarthritis of the hip. $J$ Bone Joint Surg Br 2006;88:592-600. 
15. De Smet K. Pattyn C, Verdonk R. Early results of primary Birmingham hip resurfacing using a hybrid metal on metal couple. Hip International. 2002;12:158-62.

16. Treacy RB, McBryde CW, Shears E, Pynsent CP. Birmingham Hip Resurfacing, A minimum follow-up of ten years. J Bone Joint Surg Br 2011;93:27-33.

17. Steffan R, Palan J, Beard D, et al. The five-year results of the Birmingham Hip Resurfacing arthroplasty. J Bone Joint Surg 2007;90: 436-41.

18. Rose V, Baruah BD. Resurfacing Arthroplasty of the hip for avascular necrosis of the femoral head. J Bone Joint Surg Br 2010;92: 922-8.

19. Banerjee, M, Bouillon B, Banerjee C, et al. Sports activity after total hip resurfacing. Am J Sports Med 2010;38:1229-36.

20. Valle C. Initial American Experience with Hip Resurfacing Following FDA Approval. Clin Orthop 2009;467:72-8.

21. Narvani A, Nwaboku H, Bajekal R. Sporting Activity Following Birmingham Hip Resurfacing. Int J SPorts Med 2006;27:505-7.

22. Larbpaiboonpong, V. The early outcome of Birmingham hip resurfacing: an independent Thai surgeon experiences. J Med Assoc Thai. 2009;92(Suppl 6):134-140.

23. Kim WY, Ji JH, Park SE, et al. Birmingham Resurfacing Hip Joint Arthroplasty: Minimum 5 Year follow-up study. J Korean Hip Soc 2007;19:77-81.

24. Heilpern G. A Series of 110 Consecutive Hips with a minimum of five-year clinical and radiological follow-up. Journal of Bone and Joint Surgery, Br. 2008;90:137-1142.

25. Madhu TS, Akula MR, Raman RN, et al. Birmingham Hip Resurfacing: An independent single surgeon's experience at seven-year follow up. J Arthroplasty. 2011;26:1-8.

26. Reito A, Puolakka T, Pajamäki J. Birmingham Hip Resurfacing: five to eight year results. Int Orthop 2011;35:1119-24.

27. Malek I, Hashmi M, Holland JP. Socio-economic impact of Birmingham hip resurfacing on patient employment after ten years. Int Orthop 2011;35:1467-70.

28. Khan M, Kuiper JH, Edwards D, et al. Birmingham Hip Arthroplasty, five to eight years of prospective multicenter results. $J$ Arthroplasty 2009;24:1044-50.

29. Hing CB, Back DL, Bailey M, et al. The Results of primary Birmingham hip resurfacing at a mean of five years. An independent prospective review of the first 230 hips. J Bone Joint Surgery 2007;89:1431-8.

30. Cibulka MT, White DM, Woehrle J, et al. Hip Pain and Mobility Deficits - Hip Osteoarthritis: Clinical Practice Guidelines linked to the International Classification of Functioning, Disability, and Health from the Orthopaedic Section of the American Ohysical therapy Association. J Orthop Sports Phys Ther 2009;39:A1-25. 